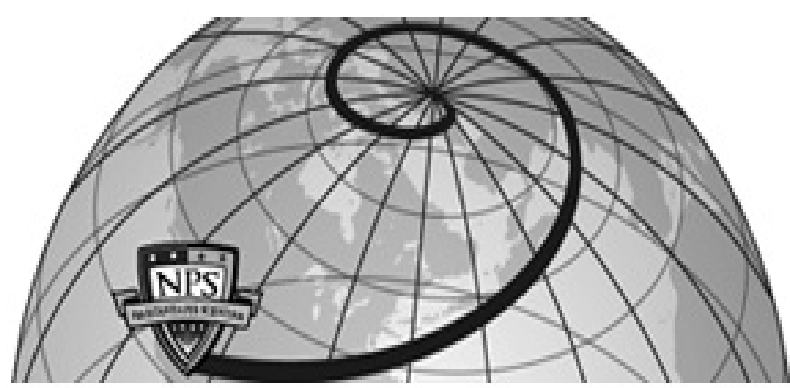

Calhoun: The NPS Institutional Archive DSpace Repository

Fuel Distribution Effects on Pulse Detonation Engine Operation and Performance

Brophy, C.M.; Hanson, R.K.

Journal of Propulsion and Power, Volume 22, No. 6, November - December 2006. https://hdl.handle.net/10945/44954

This publication is a work of the U.S. Government as defined in Title 17, United States Code, Section 101. Copyright protection is not available for this work in the United States.

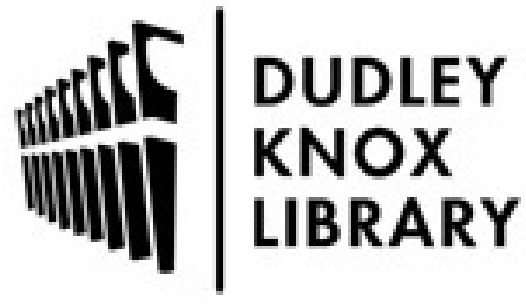

http://www.nps.edu/library
Calhoun is the Naval Postgraduate School's public access digital repository for research materials and institutional publications created by the NPS community. Calhoun is named for Professor of Mathematics Guy K. Calhoun, NPS's first appointed -- and published -- scholarly author.

Dudley Knox Library / Naval Postgraduate School 411 Dyer Road / 1 University Circle Monterey, California USA 93943 


\title{
Fuel Distribution Effects on Pulse Detonation Engine Operation and Performance
}

\author{
C. M. Brophy* \\ Naval Postgraduate School, Monterey, California 93943 \\ and \\ R. K. Hanson \\ Stanford University, Stanford, California 94305 \\ DOI: $\underline{10.2514 / 1.18713}$
}

\begin{abstract}
The validity and accuracy of performance measurements for pulse detonation engines depend on the ability to accurately measure thrust and fuel mass flow rates during system operation. Experimental tests have revealed that when fuel mass flow rates are calculated by conventional mass metering methods, incorrect values of the aggregate fuel mass in the combustor will often be calculated due to inaccurate assumptions regarding the spatial fuel distribution. The difficulty in predicting the actual fuel distribution affects the ability to achieve reliable detonations for successful operation and introduces inaccuracies directly into the performance calculations. Tunable diode laser and absorption spectroscopy techniques have been applied to provide time-resolved fuel mass fraction measurements and improve the fidelity of the specific impulse calculations. Results show that stratified fuel distributions that begin near stoichiometric at the forward end of the combustor and gradually become fuel lean near the combustor exit produce substantially higher specific impulse values than axially uniform fuel distributions with the same amount of aggregate fuel due to the ability to reliably detonate while operating at an overall lean condition. Axially uniform fuel distributions at the same average equivalence ratio demonstrated lower detonability and accordingly had lower thrust and specific impulse values.
\end{abstract}

$\begin{array}{lll} & \quad \text { Nomenclature } \\ c & = & \text { local sonic velocity } \\ F & = & \text { thrust force } \\ I_{\mathrm{sp}_{f}} & = & \text { fuel-based specific impulse } \\ \dot{m} & = & \text { mass flow rate } \\ p & = & \text { pressure } \\ T & = & \text { temperature } \\ u & = & \text { axial velocity } \\ V_{\mathrm{det}} & =\text { detonation velocity } \\ x & =\text { axial position } \\ \lambda & =\text { detonation cell size } \\ \phi & =\text { equivalence ratio }\end{array}$

Subscripts

$$
\begin{array}{ll}
a & =\text { air } \\
f & =\text { fuel } \\
\text { ifuel } & =\text { initiator fuel } \\
\text { pfuel } & =\text { primary fuel } \\
\mathrm{O} 2 & =\text { initiator auxiliary oxygen }
\end{array}
$$

\section{Introduction}

$\mathbf{P}$ ULSE detonation engines (PDEs) have received a considerable amount of renewed interest over the past 10 years due to their potential for increased performance values on a relatively low-cost engine architecture. These engines operate by repeatedly producing detonation waves that propagate through fuel/air mixtures and produce intermittent high chamber pressures which result in discrete impulses. The time-averaged result is a quasi-steady thrust. The

Christopher M. Brophy received his B.S. and M.S. aerospace engineering degrees from the Pennsylvania State University and his Ph.D. in mechanical engineering from the University of Alabama in Huntsville. He held a National Research Council postdoctoral position at the Naval Postgraduate School from 1997-1998 and is currently a research assistant professor within the Mechanical and Astronautics Department at the Naval Postgraduate School. His research interests include liquid rocket propulsion, pulse detonation engines, optical and laser diagnostics, and plume phenomenology. Dr. Brophy has published over 35 scientific papers, including 10 refereed papers, and he coauthored two review articles. He is a member of AIAA and ASME and serves as a member of the Propellants and Combustion technical subcommittee group of AIAA.

Professor R. K. Hanson earned engineering degrees from Oregon State University, Arizona State University, and Stanford University. He has been affiliated with Stanford University since 1972, and at present is the Woodard Professor of Mechanical Engineering. He served as the ME Department chair at Stanford from 1993-2003, and has been the principal advisor of more than $60 \mathrm{Ph}$.D. graduates. His research has been in the fields of laser diagnostics and sensors, shock wave physics, advanced propulsion, and combustion chemistry, and he is the author or coauthor of over 400 archival publications in these areas. Dr. Hanson is a Fellow of the American Institute of Aeronautics and Astronautics (AIAA), the American Society of Mechanical Engineers (ASME), and the Optical Society of America (OSA), and is a member of the National Academy of Engineering (NAE). He is a recipient of the Silver Medal of the Combustion Institute and the AIAA awards for Propellants and Combustion and Advanced Measurement Technology.

Received 1 August 2005; revision received 17 May 2006; accepted for publication 25 May 2006. This material is declared a work of the U.S. Government and is not subject to copyright protection in the United States. Copies of this paper may be made for personal or internal use, on condition that the copier pay the $\$ 10.00$ per-copy fee to the Copyright Clearance Center, Inc., 222 Rosewood Drive, Danvers, MA 01923; include the code $\$ 10.00$ in correspondence with the CCC.

*Research Associate Professsor, Department of Mechanical and Astronautical Engineering.

${ }^{\dagger}$ Woodard Professor of Mechanical Engineering, Department of Mechanical Engineering. 
concept of using detonations as a means for propulsion was initially proposed by Hoffmann [1] and later investigated by Nichols et al. [2] and is based on the simple concept of using a thrust tube, with one closed head-end and an open aft-end in which detonation waves are produced in a repetitive manner. A fuel/air mixture is injected at the beginning of each cycle, ignited, and the resulting deflagration wave quickly transitions into a detonation wave. After the detonation wave exits the combustor, a series of rarefaction waves travel from the exit of the combustor to the head wall, relieving the high pressure and removing the hot combustion products from the combustor. The event produces a significant pressure rise at the head wall of the combustor and ultimately thrust by the exiting momentum flux. The entire sequence needs to occur as quickly and often as possible to produce a nearly constant thrust and is often limited by the purge and refilling portion of the engine cycle.

Numerous agencies and institutions [3-7] are investigating these systems both numerically and experimentally with the goal of determining their practical performance potential. Various concepts and applications have been proposed and explored, but little experimental data exist on systems operating at expected flight conditions, frequencies, and fuel distributions representative of practical fuel injection strategies. PDE systems often fall into one of two architectures, those which use valves to control both the fuel and air mass injection into a combustion chamber and those which only valve the fuel delivery. An inherent problem with both designs is that the fuel injection must be modulated and controlled throughout the detonation cycle, either through individual fuel injectors or separate valves for premixed reactants and purge air. Regardless of the approach, achieving a consistent and uniform fuel distribution along the combustor axis is a challenge with these systems due to the highly transient conditions of the cycle.

Nearly all of the numerical and experimental test programs to date that have investigated the performance of various PDE architectures have assumed that the amount of fuel injected into the engine was done so under a nearly uniform spatial profile so that the aggregate fuel mass loading used in determining performance was a relatively straightforward calculation based on valve orifice, open duration, supply pressure, etc. Through the use of optical transmission techniques, experimental measurements of the resulting fuel distributions [ $[8,9]$ have often shown this to be an invalid assumption and that the resulting temporal/spatial fuel distributions were highly nonuniform. The implications of this characteristic can be a significant shift in the resulting specific impulse performance calculations due to the use of incorrect aggregate fuel mass fraction values.

Previous studies [8,9] at the Naval Postgraduate School (NPS) have evaluated ethylene/air, propane/air, and JP10/air mixture requirements and detonation properties in a PDE with a continuous airflow. Ethylene was chosen for most of the fuel distribution studies due to the availability of a spectroscopic fuel measurement system developed at Stanford [10] which uses absorption spectroscopy, tunable diode laser sources, and fiber optics to transmit across the combustor axis at specific locations. By integrating and averaging the calculated time-dependent mass fractions over each second of operation and using quasi-steady thrust measurements, high-fidelity specific impulse calculations can be made. The measured fuel distributions may also be provided to researchers performing computational studies of a particular PDE geometry, thereby allowing more direct and accurate computational-to-experimental comparisons of the results.

\section{Experimental Setup}

A cutaway view of the experimental setup is shown in Fig. 1, and only depicts two of the four inlet arms of the combustor. The PDE was based upon a continuous air flow path through the engine and is sometimes referred to as a "valveless" design because no valve exists for air delivery to the combustor. The primary airflow to the engine was controlled upstream of a hydrogen-fueled vitiator through a metering choke supplied with an associated total pressure and total temperature. A vitiator was used to simulate the expected combustor inlet conditions representative of supersonic flight at Mach 2.1 and an altitude of $9.0 \mathrm{~km}$. The vitiator delivered between 0.33 and $1 \mathrm{~kg} / \mathrm{s}$ of heated air at a temperature of $425 \mathrm{~K}$ to the engine inlet venturi for most of the conditions reported. Makeup oxygen was added to the vitiator products to return the molar oxygen content of the resulting air flow to $21 \%$. The nominal total pressure to the engine inlet venturi was $760 \mathrm{kPa}$ for an air mass flow rate of $0.33 \mathrm{~kg} / \mathrm{s}$ at $450 \mathrm{~K}$ and increased up to $2.38 \mathrm{MPa}$ for the $1 \mathrm{~kg} / \mathrm{s}$ air mass flow rate due to the fixed venturi throat diameter of $16.6 \mathrm{~mm}(0.655 \mathrm{in})$. The total pressure at the engine inlet venturi was sufficiently high to isolate the upstream flow from the periodic increases in backpressure downstream of the venturi.

Fuel injection was controlled by high-speed Valvetech 15060-2 solenoid valves located on each of the four distribution arms. The four distribution arms were connected to a manifold region at the forward end of the combustor which produced a coflowing region around an initiator unit. The oxygen-enriched initiator was used to initiate a detonation in the main combustor by transmitting a strong detonation from the initiator exit to the main combustion through a diffraction process. The initiator operated on an ethylene/oxygen/ nitrogen mixture at an equivalence ratio of 1.2 and had an internal volume of $259 \mathrm{~cm}^{3}$ with a varying cross section previously found to perform well over a wide range of conditions and fuels [8]. The initiator had an overall length of $250 \mathrm{~cm}$ and an exit diameter of $4.45 \mathrm{~cm}$. Fuel injection into the initiator was controlled by a single ValveTech 15060-2 solenoid valve and the oxygen injection by six Parker-Hannefin 009-0449-900 solenoid valves. A continuous air purge of approximately $0.03 \mathrm{~kg} / \mathrm{s}$ was directed through check valves and into the initiator at nominal conditions to prevent the preignition of the refresh reactants. Ignition of the resulting mixture was accomplished with a MSD 6A ignition system. The combustor consisted of a conical transition section downstream of the initiator exit that increased the initial diameter from $0.0635 \mathrm{~m}$ to the final $0.1016 \mathrm{~m}$ over a $0.1 \mathrm{~m}$ length and provided a more gradual diffraction and transmission process from the initiator unit to the main combustor. The main combustor had an exiting internal diameter of $0.1016 \mathrm{~m}$ and a nominal length of $0.585 \mathrm{~m}$ for most of the testing, but

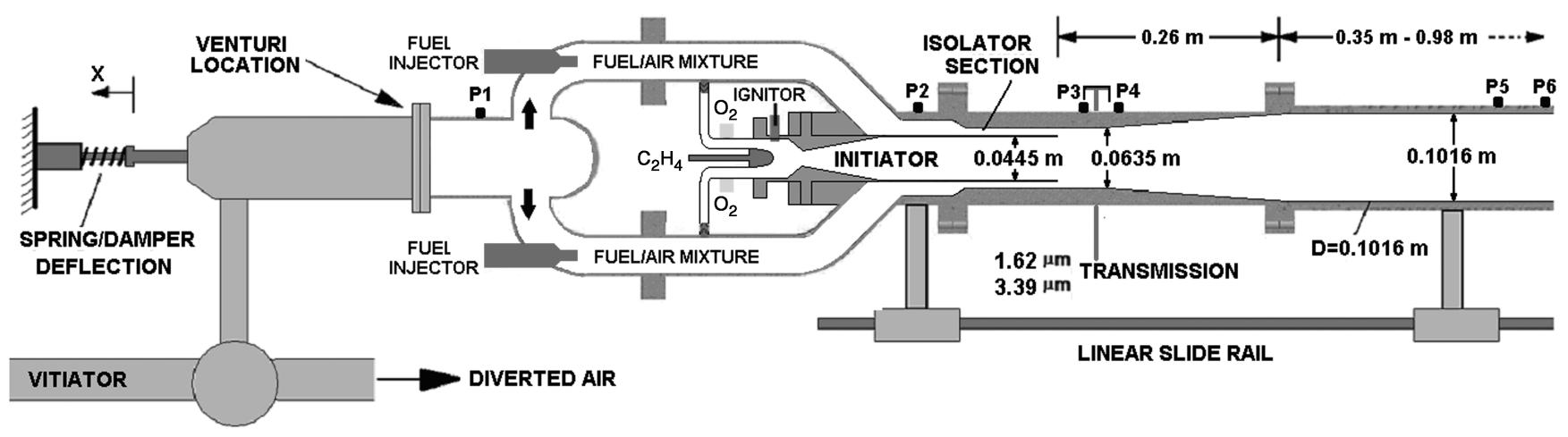

Fig. 1 NPS PDE cross-sectional view (two of four arms depicted). 


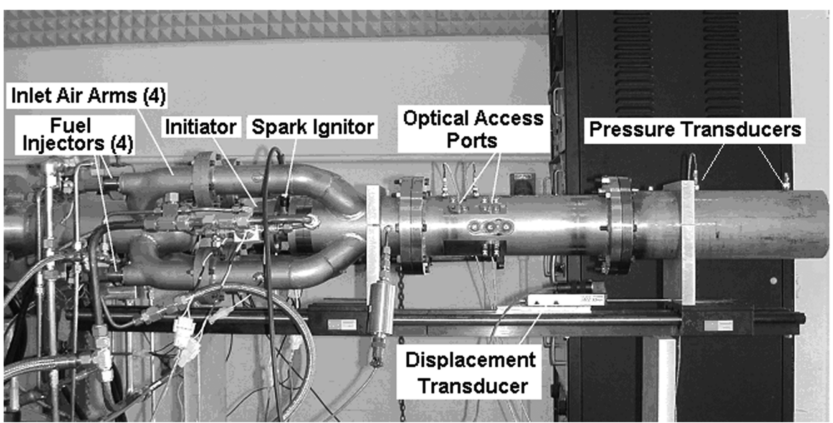

Fig. 2 Test cell view of PDE and associated hardware.

was increased to $1.24 \mathrm{~m}$ for a limited number of the later experiments. Timing of the fuel injection events and ignition sequence was controlled through the use of a BNC 500 pulse generator which enabled a series of Crydom 6203 solid state relays to control the fuel valves and ignition system.

The PDE was mounted on a low-friction linear rail on top of a multicomponent thrust stand, and thrust was determined by displacement measurements using a Novatechnic TRS 75 linear voltage division transducer and can be seen in Fig. 2. The vitiated air and the supply gases to the engine were delivered by flex lines. Calibration of the linear displacement transducer was performed after all the gas delivery lines were pressurized to their nominal pressure settings. The calibration curve was generated by both forward and backward measurements and did not show any noticeable hysteresis over much of the calibration, except near the zero load condition where a $\pm 9.3 \mathrm{~N}$ fluctuation appeared. This condition was believed to be due to friction in the linear rail at nearzero loads and was minimized by applying a preload to the combustor mounting brackets. High-frequency pressure wave traces at locations P1-P6, shown in Fig. 1, were obtained through the use of Kistler 6031B1 transducers with 5010 charge amplifiers and all supply gases were monitored by Omega PX-5500 pressure transducers. All pressure transducer output signals were within a $0-5$ VDC output level and acquired by two National Instruments PXI1000 instrumentation racks with associated low-speed 16-bit (6031E) and high-speed 12-bit (6115) data acquisition cards configured for 0-5 VDC input. The low-speed pressure and thermocouple data were acquired at $1 \mathrm{kHz}$ and the high-speed pressure transducer data and optical transmission measurements were acquired simultaneously at $1 \mathrm{MHz}$ per channel.

Diode laser sensors are well-suited for monitoring in the harsh PDE environment because of their nonintrusive nature, robustness, and compactness. Among all the laser-based diagnostic methods, techniques based on direct absorption appear to be specially attractive because of the relative simplicity of implementation and data interpretation. A sensor based on the absorption spectrum of the Q-branch of $\mathrm{C}_{2} \mathrm{H}_{4}$ over the $6145-6151 \mathrm{~cm}^{-1}(1.62 \mu \mathrm{m})$ spectral region was developed for this work as detailed in [10]. The temperature dependence of the shape of this Q-branch absorption feature has been also studied [9]. Therefore the spectral information scanned by this sensor enables simultaneous measurement of $\mathrm{C}_{2} \mathrm{H}_{4}$ fuel concentration and temperature.

Figure 3 provides a schematic of the experimental arrangement for the $\mathrm{C}_{2} \mathrm{H}_{4}$ fuel measurements. On the pitch side of the sensor, as shown in Fig. 3, the laser source was coupled into a fiber, and the fiber held in a specially machined mount. The mount was rigidly attached to the engine via threaded bolts. On the detection side, an integrating sphere and an InGaAs detector were mounted on an L-shaped bracket, and the bracket also rigidly attached to the engine. This optical engineering of the sensor has proved to be easy to align, robust during shipment and repeated experiments, and resistant to noises caused by beamsteering, emission, and mechanical vibration. The $1.62 \mu \mathrm{m}$ diode laser was current modulated at $5 \mathrm{kHz}$ during the experiments to register the Q-branch absorption. The transmitted laser beam was monitored by the InGaAs detector, then converted to $\mathrm{C}_{2} \mathrm{H}_{4}$ concentration.

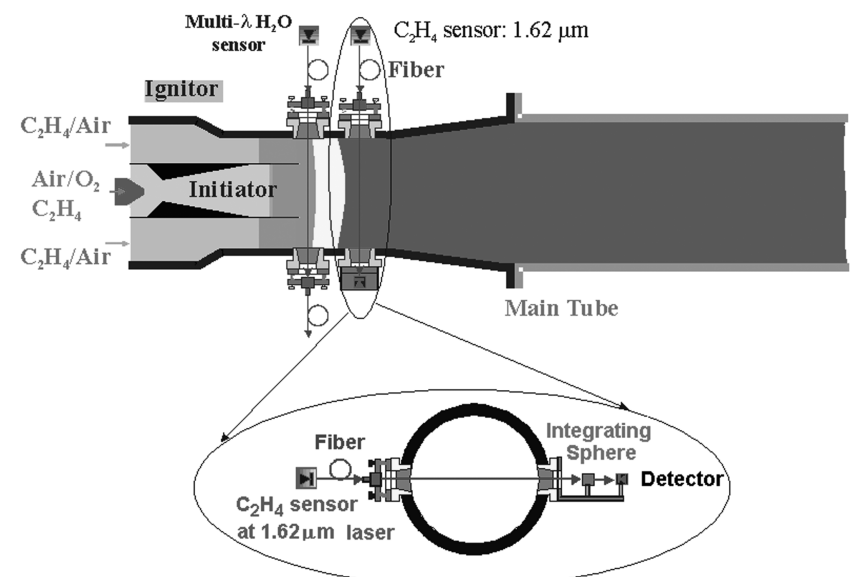

Fig. 3 Experimental arrangement for $\mathrm{C}_{2} \mathrm{H}_{4}$ fuel measurements.

\section{PDE Cycle and Operation}

The operational cycle of the NPS pulse detonation engine is shown in Fig. 4. The cycle begins with air flowing through the engine and purging the previous combustion products (4a). During the second stage, fuel is injected into the air flow and carried towards the main combustor while a portion is directed through the initiator (4b). Stage $4 c$ represents the end of the primary fuel injection event, and the injection of the initiator reactants. The initiator mixture of ethylene, oxygen, and nitrogen is at an equivalence ratio of 1.2 and is loaded into the initiator and mixed before ignition (4d). Stage 4e shows the ignition of the initiator mixture and the formation of a detonation wave. The detonation wave then progresses through the mixture and successfully diffracts into the mixture in the main combustor (4f). Stage $4 \mathrm{~g}$ shows the detonation wave exiting the main combustor while the combustion products continue to expand upstream of the initiator exit plane. Finally, after the detonation wave exits the main combustor, a series of rarefaction waves reduces the pressure inside the combustor and the combustion products are purged from the engine (4h).

\section{Results}

The engine was operated at $40 \mathrm{~Hz}$ using ethylene as a fuel over an equivalence ratio range of $0.6-1.7$. Detonations were observed for all equivalence ratios above 0.95 and were primarily dependent on the local equivalence ratio near the initiator exit plane. When fuel-lean conditions existed near the initiator exit, an increase in the number of failed detonation cycles occurred due to the decreased reactivity [6] of lean hydrocarbon/air mixtures and their relatively large detonation cell sizes. These conditions significantly inhibited the successful initiation, diffraction, and propagation of a detonation wave. They were minimized and/or eliminated by distributing near-stoichiometric conditions at the head-end of the combustor where the detonation is initiated and then have the detonation propagate into much leaner conditions near the aft-end. The nonuniform axial fuel distributions were inherently a stratified fuel injection profile due to the transient nature of the fuel injectors and unsteady flowfield effects. Fuel mass fraction results from normal operation of the system are shown in Figs. $\underline{5 a}$ and $\underline{5 b}$. Figure $\underline{5 a}$ depicts the temporal fuel mass fraction for ethylene measured $5 \mathrm{~cm}$ aft of the initiator exit over eight cycles at a operational frequency of $40 \mathrm{~Hz}$. The time scale for one of the cycles is expanded in Fig. $5 \mathrm{~b}$ and clearly shows that the temporal fuel distribution was highly nonuniform. Propagation of the bulk flow through the combustor path then resulted in a nonuniform axial fuel distribution. The mixture initially delivered to the combustor was lean and then proceeded to become rich at the end of the fuel injection event. Evidence of the detonation arrival at the measurement location can be seen at the end of each fueling cycle by the large spike in mass fraction and was due to beam steering and emission from the detonation wave. The temporal trace of the fuel mass fraction may be approximately mapped to a corresponding 


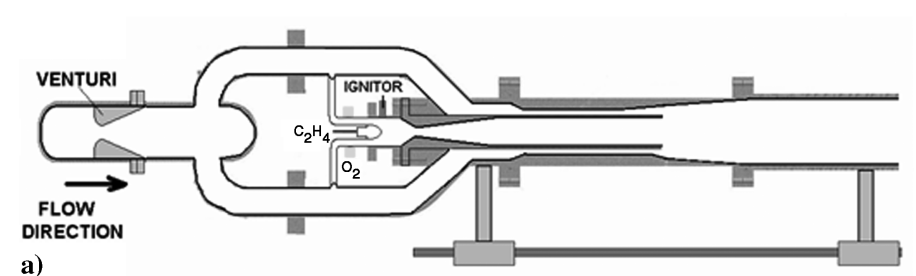

a)

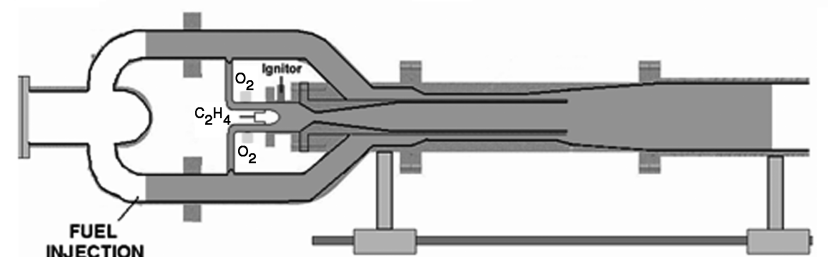

b)

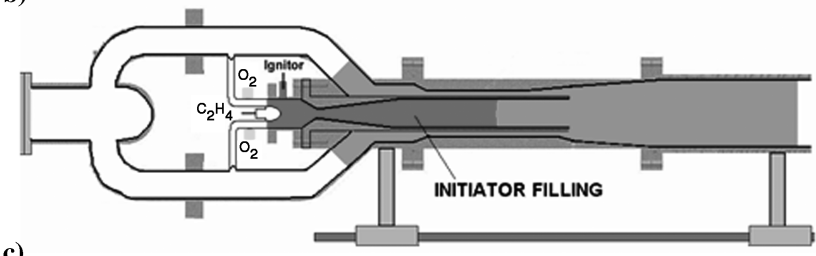

c)

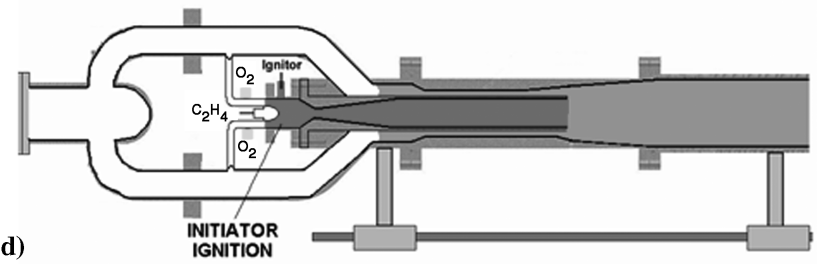

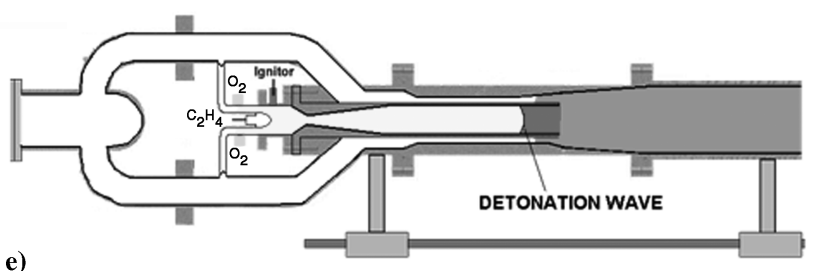
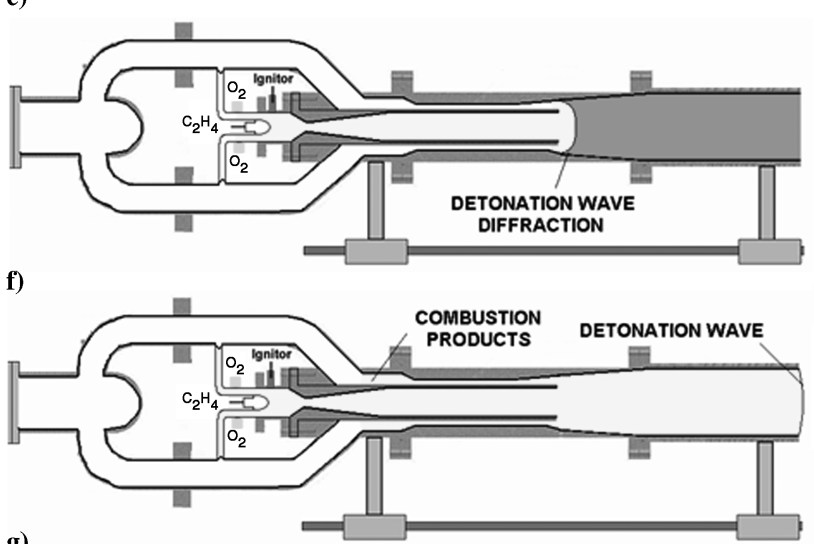

g)

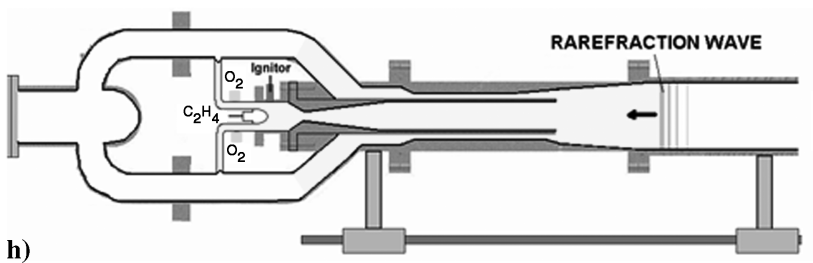

Fig. 4 Valveless PDE cycle.

spatial distribution, as shown in Fig. 6, because the reactants were flowing past the sensor at a determined velocity. The amount of fuel residing in the combustor per cycle was then calculated by assuming that the distribution was frozen the moment the detonation wave arrived at the fuel sensor. By calculating the bulk flow velocity within the combustor, the axial fuel distributions were estimated and integrated over the combustor volume to obtain the aggregate amount of fuel. Two average equivalence ratios are shown in Fig. $\underline{6}$, one at an average equivalence ratio of 1.28 and one at an average equivalence ratio of 0.88 . Additionally, each equivalence ratio has two curves, one representing a uniform spatial distribution of fuel and the other a nonuniform distribution. Although the curves for each average equivalence ratio case are substantially different, the same aggregate amount of fuel resided within the combustor for each equivalence ratio case. The uniform spatial fuel distributions depicted in Fig. $\underline{6}$ were generated by allowing the fuel injection event for each cycle to reach a steady-state condition before turning off the fuel injectors, thus allowing the transient portion of fuel injection profile to flow out of the combustor. The nonuniform spatial profiles are two of the common test conditions that the engine normally operated at to prevent excessive overfilling of the reactants. Under practical engine operation, fuel not used for combustion within the engine would result in a performance penalty due to a large portion of the injected fuel not being used for thrust production.

The fuel distributions for each test condition were integrated over the combustor volume and then used for calculating the specific impulse of the engine for each test. Corresponding thrust measurements for each condition were also required to calculate the resulting specific impulse values. Figure 7 displays the vitiated air temperature and gross thrust profile during a test where the operating frequency of the engine was stepped from 10 to $40 \mathrm{~Hz}$ for demonstration purposes only. The vitiated air was directed into the engine flow path at $6 \mathrm{~s}$ and the engine was engaged at $12.5 \mathrm{~s}$. The various "steps" depicted on the thrust profile correspond to operating frequencies of $10,20,30$, and $40 \mathrm{~Hz}$ during a ramped frequency experiment. Although the gross thrust term is more convenient to modelers, the net thrust for the test conditions could be calculated by subtracting a stream thrust of approximately $24 \mathrm{~N}$ from the gross thrust reported. Because the flowfield just downstream of the inlet venturi where the stream thrust was calculated varies in time due to the forward compression of the incoming air by each combustion event, further analysis would be required before this value could be applied quantitatively. Therefore the gross thrust reported in Fig. 7 is included in the specific impulse calculation for comparison to other systems. The fuel mass used in the specific impulse calculations was also corrected for the use of the initiator for the current engine configuration. The true "fuel" mass used in the fuel-based specific impulse calculation is composed of the mass of the fuel in the main combustor as well as the initiator. Additionally, the amount of auxiliary oxygen used in the initiator must be accounted for and treated as fuel because it must be carried along on such a propulsion system. The resulting fuel-based specific impulse equation is

$$
I_{\mathrm{sp}_{f}}=\frac{F}{m_{f} g}=\frac{F}{\left(m_{\mathrm{pfuel}}+m_{\mathrm{ifuel}}+m_{\mathrm{O} 2}\right) g}
$$

Equation (1) reveals the advantages of operating a system without the need for auxiliary oxygen in the system. The fuel-based specific impulse for the system will likely only increase as the amount of auxiliary oxygen is reduced or eliminated. Although pure fuel/air PDE systems exist, they are often limited to frequencies below $30 \mathrm{~Hz}$ and possess substantial total pressure losses during the filling and blowdown portions of the cycle due to the presence of turbulence enhancing devices for deflagration-to-detonation transition (DDT) purposes. Performance losses due to drag-producing obstacles typically range from 10-35\% for most fuel/air PDE systems which use wall spirals and tabs [11]. Alternate detonation initiation strategies continue to be evaluated which may reduce the amount of turbulence devices required and possibly even eliminate them all together.

The fuel-based specific impulse performance results for the configurations and conditions evaluated are shown in Fig. $\underline{8}$ along with a semi-empirical performance model from Caltech $[11,12]$ based upon analytical and ballistic impulse measurements for simple 


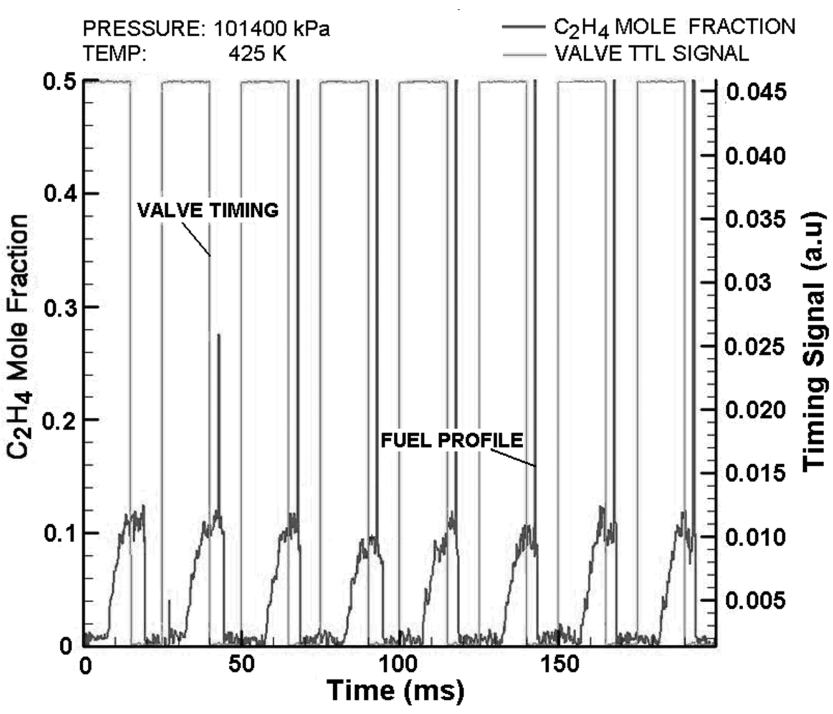

a) Multiple fuel injection cycles

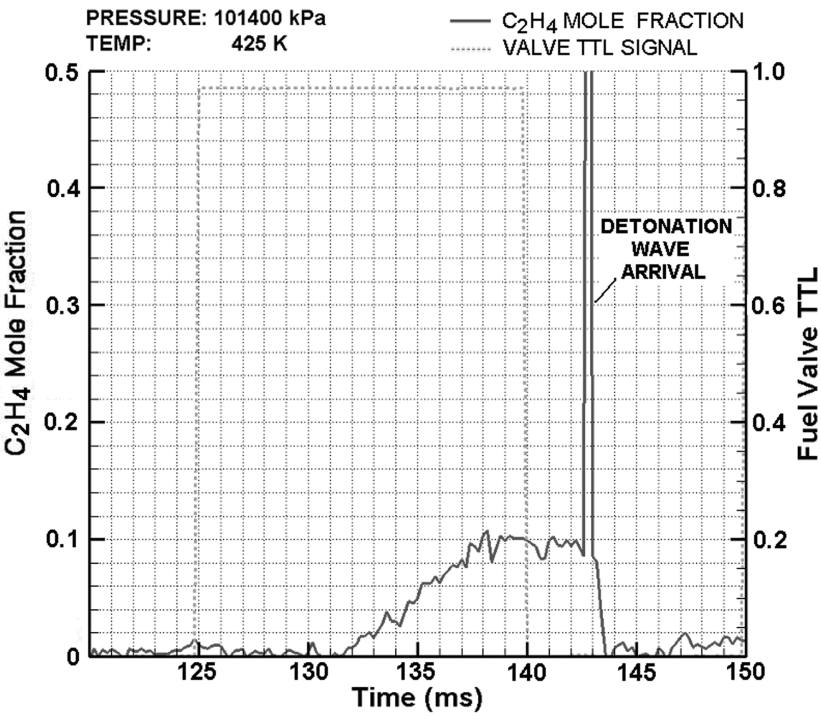

b) Single cycle

Fig. 5 Fuel mass fraction vs cycle time at $5 \mathrm{~cm}$ after initiator exit.

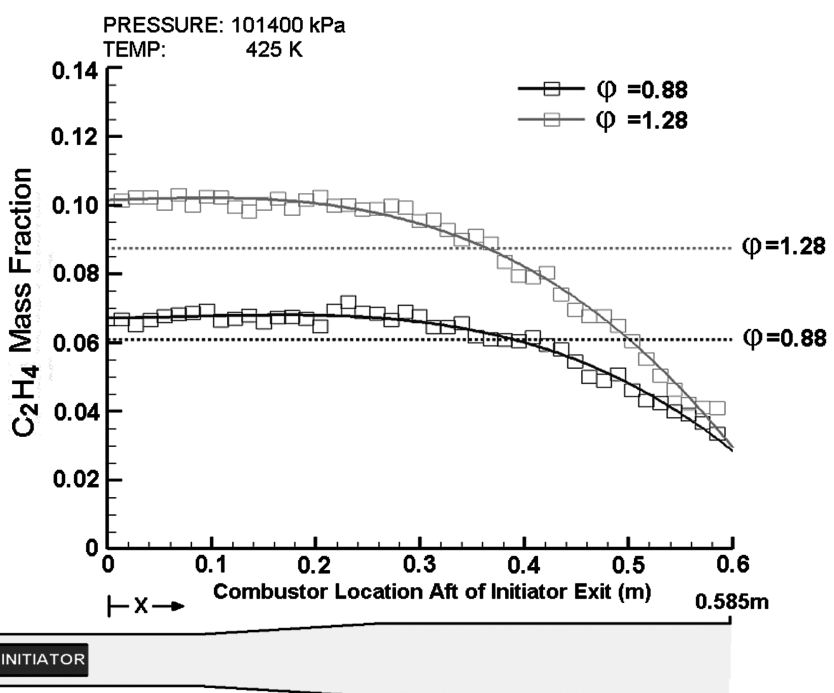

Fig. 6 Fuel mass fraction vs combustor location.

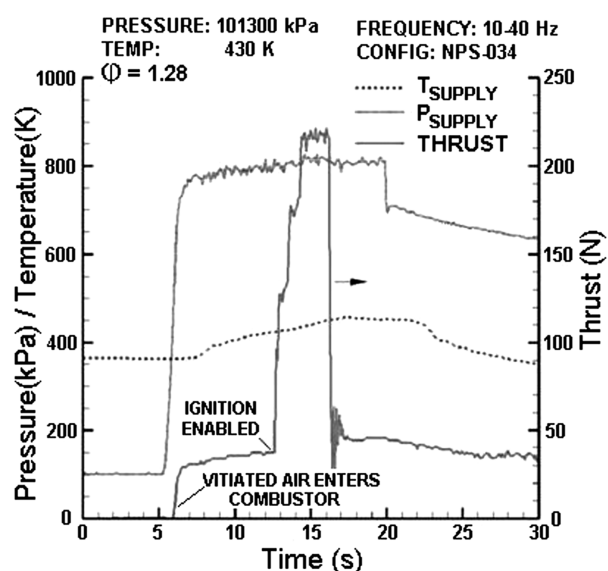

Fig. 7 Typical engine parameters vs time for a $10-40 \mathrm{~Hz}$ stepped frequency run.

combustors operating over one cycle. The model is for static conditions and likely represents a near maximum performance reference for PDEs. Because the model was produced from singlecycle tests, it is presented for a convenient reference and should be viewed accordingly. The results show a trend that follows the model and clearly reveal the performance penalty of the initiator. The NPS 585 configuration was substantially shorter than the NPS 1240 configuration which had a larger main combustor volume due to the increased main combustor length. The result was an initiator volume ratio (IVR) of $1.5 \%$ (vs $4.4 \%$ for the NPS 585 configuration) which substantially reduced the performance penalty of the initiator reactants due to the increased volume of the main combustor. The IVR is defined as the volume of the initiator divided by the total combustor volume. The solid symbols in Fig. 8 were generated with fuel mass fraction profiles similar to those depicted in Fig. 6 for the spatially nonuniform conditions.

Spatially-uniform fuel fill fractions were also performed for the NPS 585 configuration and are represented as open squares in Fig. 8. The amount of fuel "spilled" out the combustor exit to generate the uniform profiles was not considered in the specific impulse calculations. It can be seen that the effect of the nonuniform fill profile resulted in a benefit only for lean average equivalence ratios. This was believed to be due to the fact that if any of the oxygen in the

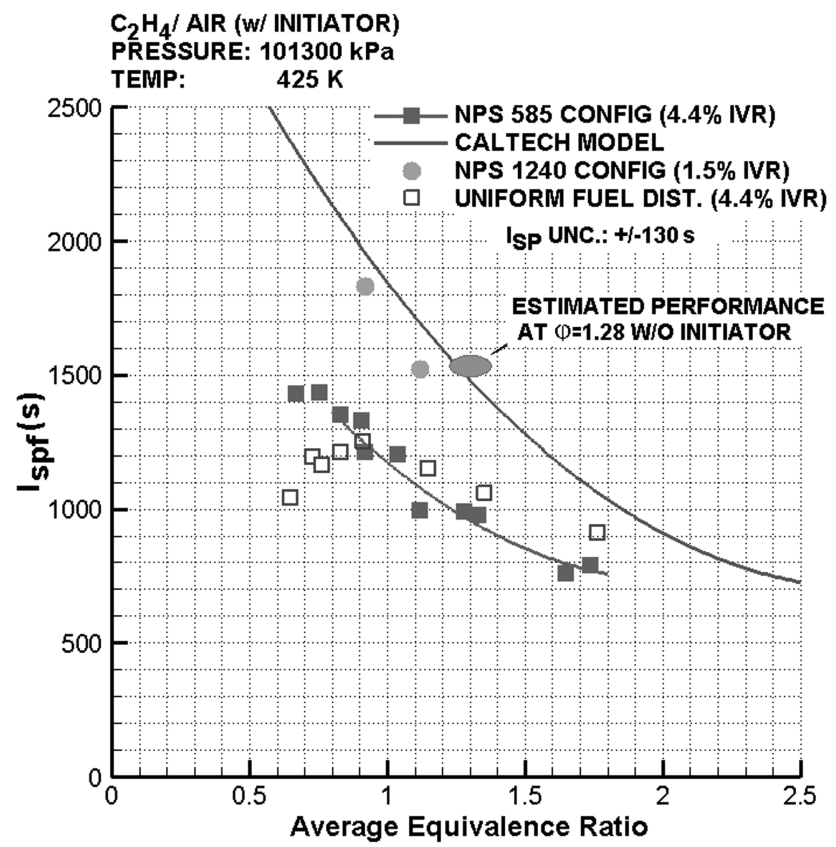

Fig. 8 Fuel-based specific impulse vs equivalence ratio for NPS PDE configurations. 
combustor was not used during combustion for the rich conditions, there was an overall loss of energy conversion that would have occurred for a uniform distribution of the same amount of fuel. The lean combustor configurations benefit from the operational aspect that it is easier to initiate stoichiometric or slightly fuel-rich conditions than fuel-lean conditions due to the representative cell size and associated sensitivity of the mixture [13]. This allowed for easier initiation and/or transmission of a detonation wave into the main combustor increasing the likelihood of a good detonation cycle and high representative thrust levels. Therefore, the nonuniform axial fuel distributions would be advantageous for an operational engine by promoting high detonability while allowing the engine to operate at overall fuel-lean conditions to maximize specific impulse. The results would approximate the benefits of partial fill scenarios [14], which have been shown to be a method to increase the specific impulse, but at a penalty of lowering overall thrust levels.

The possible errors due to incorrectly calculating the fuel mass fraction are shown in Fig. 9. Only the NPS 585 configuration data for the nonuniform fill conditions are shown in Fig. 9 to stress the importance of properly characterizing the fuel distribution within a combustor. It can be clearly seen that if a uniform axial fuel distribution was assumed for a specified fuel-injector setting, based on valve orifice, open duration, and supply pressures, the resulting fuel-based specific impulse values would be substantially lower due to a higher calculated aggregate fuel mass fraction than was actually within the combustor during those tests. Because the thrust force measured during the test is held constant for both calculations, Eq. (1) results in a reduction of the fuel-based specific impulse value due to the increased amount of fuel included in the denominator. The magnitude of the error approaches $35 \%$ for the fuel-lean conditions and decreases slightly as the mixture equivalence ratios increase due to the reduced influence of the initiator reactants in the calculation.

The absolute uncertainties in the thrust force were determined to be $\pm 5.5 \mathrm{~N}$ and the maximum uncertainties in the fuel mass measurement were reported as $3 \%$ over the equivalence ratio range evaluated resulting in a maximum absolute uncertainty of $\pm 130 \mathrm{~s}$ on the fuel-based specific impulse calculations over the equivalence range evaluated. As thrust levels increase and optical transmission paths are optimized on future tests, the reported uncertainty will likely be substantially reduced.

\section{Summary and Conclusions}

The fuel mass fraction distribution within a PDE inherently affects the overall system performance in terms of both the initiation

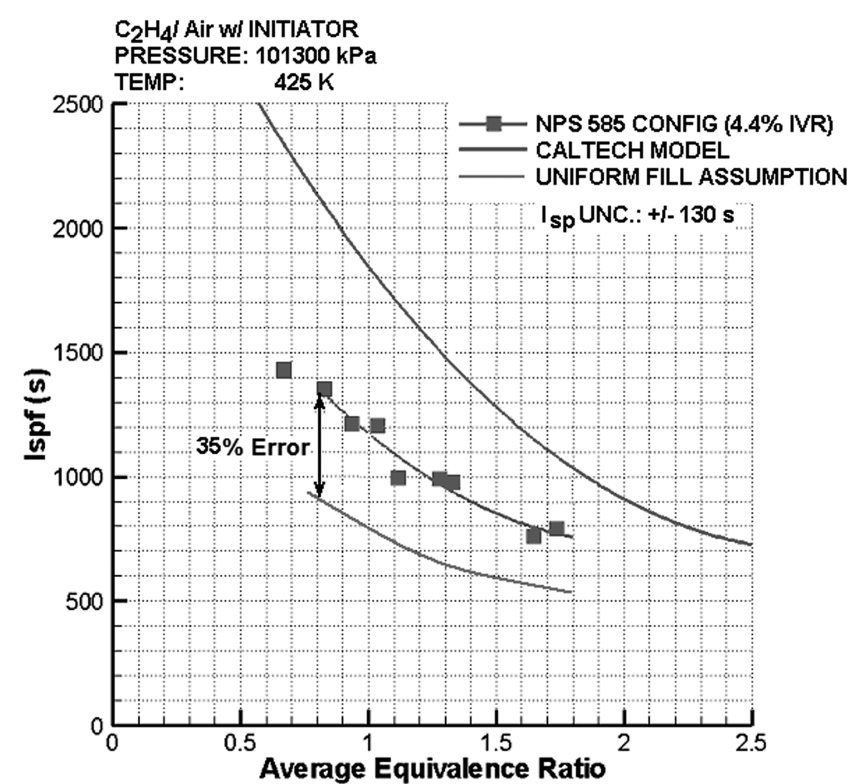

Fig. 9 Relative error in calculated $I_{\mathrm{sp}_{f}}$ of uniform fill assumption to actual fuel distribution. characteristics and the resulting fuel-based specific impulse performance values. This is true for valved or continuous flow devices which use transient fuel injection or premixed fueling strategies. A large operational benefit exists for a stratified axial fuel distribution when a near-stoichiometric mixture exists near the initiation end of a combustor to promote rapid ignition/DDT and a leaner mixture is present near the combustor exit. Once a detonation is established, the detonation wave can more easily propagate into the less reactive mixture. The common existence of such distributions for transient fuel injection events generates the need to accurately determine the time-varying fuel concentration within a PDE combustor and is extremely important for producing high-fidelity performance values. The results reveal a performance penalty for overall fuel-rich conditions with a stratified fuel distribution and a benefit for overall fuel-lean conditions when compared to uniform fuel distribution mixtures with the same aggregate fuel mass fraction. The increase in fuel-based specific impulse for overall lean conditions with a stratified axial fuel mass fraction is similar to the benefits of partial fill scenarios but allows for higher thrust levels to be produced due to the use of more combustor volume for combustion and not simply gas dynamic tamping. The application of an optical fuel measurement system has proven to be an invaluable tool for the accurate profiling of the spatial fuel mass fraction variation within a PDE combustor over the fuel injection portion of the engine cycle. The characterization of actual fuel distributions in a multicycle PDE test therefore allows a more appropriate comparison of experimental-to-computational results by allowing the modelers to input the exact experimental fuel profiles into simulations of hardware configurations.

\section{Acknowledgments}

This research was supported by the Office of Naval Research with Gabriel Roy as program manager. The authors would also like to thank Jose Sinibaldi at the Naval Postgraduate School and Ma Lin from Stanford for their contributions to this effort.

\section{References}

[1] Hoffmann, H., "Reaction Propulsion by Intermittent Detonative Combustion," Ministry of Supply, Germany, Volkenrode Translation, 1940.

[2] Nicholls, J., Wilkinson, H., and Morrison, R., "Intermittent Detonation as a Thrust Producing Mechanism," Jet Propulsion, Vol. 27, No. 5, 1957, pp. 534-541.

[3] Harris, P., Guzik, S., and Stowe, R., "Design Methodology for a Pulse Detonation Engine as a Ramjet Replacement," AIAA Paper 2004-3400, July 2004.

[4] Povinelli, L., and Lee, J-H., "Role of Air-Breathing Pulse Detonation Engines in High Speed Propulsion," IAF Paper IAF-01-S.5.01, Oct. 2001

[5] Kailasanath, K., "Recent Developments in the Research on Pulse Detonation Engines," AIAA Journal, Vol. 41, No. 2, 2003, pp. 145-159.

[6] Schauer, F., Sturud, J., and Bradley, R., "Detonation Initiation Studies and Performance Results for Pulse Detonation Engines," AIAA Paper 2001-1129, Jan. 2001.

[7] Lupkes, K. R., Anderson, S. D., and Tonouchi, J. H., "Recent Advances in Multiple Combustor Pulse Detonation Engine Development," 16th International Symposium on Airbreathing Engines [CD-ROM], AIAA, Aug.-Sept. 2003.

[8] Brophy, C. M., Sinibaldi, J. O., Netzer, D. W., and Johnson, R. G., "Operation of a JP-10/Air Pulse Detonation Engine," AIAA Paper 2000-3591, July 2000.

[9] Brophy, C. M., Sinibaldi, J. O., Ma, L., and Klingbeil, A. E., "Effects of Non-Uniform Mixture Distributions on Pulse Detonation Engine Performance," AIAA Paper 2005-1304, Jan. 2005.

[10] Ma, L., Sanders, S. T., Jeffries, J. B., and Hanson, R. K., "Monitoring and Control of a Pulse Detonation Engine using a Diode-Laser Fuel Concentration and Temperature Sensor," Proceedings of the Combustion Institute, Vol. 29, 2002, pp. 161-166.

[11] Wintenberger, E., Austin, J., Cooper, M., Jackson, S., and Shepherd, J. E., "An Analytical Model for the Impulse of a Single-Cycle Pulse Detonation Tube," Journal of Propulsion and Power, Vol. 20, No. 4, 2004, pp. 765-767.

[12] Cooper, M., Shepherd, J. E., and Schauer, F., "Impulse Correlation for 
Partially Filled Detonation Tube Impulse," Journal of Propulsion and Power, Vol. 20, No. 5, 2004, pp. 811-819.

[13] Lee, J., "Dynamic Parameters of Gaseous Detonations," Annual Review of Fluid Mechanics, Vol. 16, 1984, pp. 311-316.

[14] Li, C., and Kailasanath, K., "Partial Fuel Filling in Pulse Detonation
Engines," Journal of Propulsion and Power, Vol. 19, No. 5, 2003, pp. 908-916.

J. Powers Associate Editor 